\title{
Convection-enhanced Delivery of Free Gadolinium with the Recombinant Immunotoxin MR1-1
}

\author{
Dale Ding, BS, \\ School of Medicine Duke University Medical Center DUMC Box 3050220 Sands Building, \\ Research Drive Durham, NC 27710 Phone: 919-668-5370 Fax: 919-684-9045 \\ dale.ding@duke.edu
}

Charles W Kanaly, MD,

Division of Neurosurgery, Department of Surgery Duke University Medical Center Box 3050220

Sands Building, Research Drive Durham, NC 27710 Phone: 919-668-5370 Fax: 919-684-9045

charles.kanaly@duke.edu

\author{
Darrell D Bigner, MD, PhD, \\ Department of Pathology Duke University Medical Center The Preston Robert Tisch Brain Tumor \\ Center at Duke Box 3156 Durham, NC 27710 Phone: 919-684-5018 Fax: 919-684-6458 \\ bigne001@mc.duke.edu
}

\section{Thomas J Cummings, MD,}

Department of Pathology Box 3712 Duke University Medical Center Durham, NC 27710 Phone: 919-684-6592 Fax: 919-681-7634 cummi008@mc.duke.edu

\author{
James E Herndon II, PhD, \\ Department of Biostatistics and Bioinformatics 8034 Hock Plaza Duke University Medical Center \\ Durham, NC 27710 Phone: 919-668-8145 Fax: 919-681-8028 james.herndon@duke.edu \\ Ira Pastan, MD, and \\ Laboratory of Molecular Biology Center for Cancer Research National Cancer Institute National \\ Institutes of Health Bethesda, MD 20892 Phone: 301-496-4797 Fax: 301-402-1344 \\ pastani@mail.nih.gov
}

\section{Raghu Raghavan, PhD}

Therataxis, LLC 1101 East $33^{\text {rd }}$ Street Suite B305 Baltimore, MD 21218 Phone: 443-451-7154

Fax: 443-451-7157 raghu@therataxis.com

\section{Abstract}

\begin{abstract}
Purpose-A major obstacle in glioblastoma (GBM) therapy is the restrictive nature of the bloodbrain barrier (BBB). Convection-enhanced delivery (CED) is a novel method of drug administration which allows direct parenchymal infusion of therapeutics, bypassing the BBB. MR1-1 is a novel recombinant immunotoxin that targets the GBM tumor-specific antigen EGFRvIII and can be delivered via CED infusion. However, drug distribution via CED varies dramatically, which necessitates active monitoring. Gadolinium conjugated to diethylenetriamine penta-acetic acid (Gd-DTPA) is a commonly used MRI contrast agent which can be co-infused with therapies using CED and may be useful in monitoring infusion leak and early distribution.
\end{abstract}

Experimental design-Forty immunocompetent rats were implanted with intracerebral cannulas that were connected to osmotic pumps and subsequently randomized into four groups

John H Sampson, MD, PhD, MHSc (Corresponding Author) Division of Neurosurgery, Department of Surgery Duke University Medical Center The Preston Robert Tisch Brain Tumor Center at Duke Box 3050220 Sands Building, Research Drive Duke University Medical Center Durham, NC 27710 Phone: 919-668-5370 Fax: 919-684-9045 john.sampson@duke.edu. 
that each received $0.2 \%$ human serum albumin (HSA) mixed with a different experimental infusion: 1) $25 \mathrm{ng} / \mathrm{mL}$ MR1-1; 2) $7 \mu \mathrm{mol} / \mathrm{mL}$ Gd-DTPA; 3) $25 \mathrm{ng} / \mathrm{mL}$ MR1-1 and $7 \mu \mathrm{mol} / \mathrm{mL}$ GdDTPA; 4) $250 \mathrm{ng} / \mathrm{mL}$ MR1-1 and $7 \mu \mathrm{mol} / \mathrm{mL}$ Gd-DTPA. The rats were monitored clinically for six weeks then necropsied and histologically assessed for CNS toxicity.

Results-All rats survived the entirety of the study without clinical or histological toxicity attributable to the study drugs. There was no statistically significant difference in weight change over time among groups ( $\mathrm{p}>0.999)$.

Conclusion-MR1-1 co-infused with Gd-DTPA via CED is safe in the long-term setting in a pre-clinical animal model. Our data supports the use of Gd-DTPA, as a surrogate tracer, coinfused with MR1-1 for drug distribution monitoring in patients with GBM.

\section{Keywords}

Immunotoxins; brain; drug delivery systems glioblastoma; gadolinium

\section{Introduction}

One of the main impediments of successful drug therapy to the brain is the BBB, which restricts the CNS entry of many systemically administered agents, and especially larger biologic molecules such as antibodies, by either limiting or completely inhibiting drug penetration into neural tissue. Even the most effective therapies, delivered systemically, will become dose-limited by drug-related toxicities. In 1994, Bobo et al. devised a method of circumventing the BBB by strategically placed intracranial catheters that deliver drugs directly into the tumor bed, in a process termed CED [1]. CED allows for the delivery of drugs at a much high concentration than what could be achieved with systemic administration and also allows for treatment with novel agents that cannot be administered systemically. This has opened to door to the development of many novel therapies for malignant brain tumors[2-6], Parkinson's disease[7, 8], Gaucher disease[9-11], epilepsy[12, 13], and stroke[3].

GBM is classified by the World Health Organization (WHO) as a grade IV brain tumor. It afflicts approximately 20,000 people annually in the United States and comprises approximately $50 \%$ of primary CNS gliomas [14]. The standard of care after initial diagnosis is gross total resection (GTR) followed by a course of temozolomide with external beam radiation therapy (XRT), but unfortunately this treatment yields a median survival of only slightly more than 14 months[15]. Moreover, radiation with concurrent temozolomide has not been shown to have any survival benefit when compared with radiation alone for patients who do not have a methylated MGMT promoter indicating MGMT gene silencing [16]. Clearly, stronger, more effective treatment options are desperately needed for this disease.

MR1-1 is a recombinant immunotoxin comprised of a monoclonal antibody fragment specific for the EGFRvIII mutation conjugated to a genetically modified truncated Pseudomonas exotoxin, PE-38. EGFRvIII is a truncated form of the epidermal growth factor receptor (EGFR) that has a constitutively active tyrosine kinase domain, greatly increasing tumorigenicity $[17,18]$. It is expressed in approximately $40 \%$ of GBMs but is not present in normal human tissue, making it an ideal target for glioma-specific therapy [19, 20]. The truncated exotoxin PE-38 retains its natural cytotoxic property of inhibiting elongation factor 2 via ADP ribosylation, but has lost the ability of its precursor Pseudomonas exotoxin to bind cells secondary to truncation of domain Ia/Ib [21, 22]. Therefore, the combination immunotoxin MR1-1 possesses cytoxicity from PE-38 that is directed against those tumor cells expressing EGFRvIII. Early pre-clinical studies of MR1-1 in murine EGFRvIII 
expressing tumor models have shown promising results, although the exact mechanism of MR1-1 has yet to be completely elucidated [23].

While CED can be an effective method to deliver high concentrations of powerful antitumor therapies directly into tumor tissue, its potency is restricted by the lack of appropriate drug distribution in a number of cases. Leakage of infusate into subarachnoid and intraventricular spaces can lead to poor drug delivery and low efficacy [24]. Therefore, clinical trials that utilize CED will need to also closely monitor drug infusion in order to ensure an adequate intraparenchymal volume of distribution. Much pre-clinical and clinical work has been done to image or predict the distribution and delivery of drug in the brain, including imaging modalities such as T2-weighted MRI[25], diffusion-weighted MRI[26, 27], single photon emission computed tomography (SPECT) imaging[24] and dynamic contrast-enhanced imaging[28]. Additionally, CED co-infusion of surrogate tracers such as Gd-albumin conjugates[29-31], Gd-loaded liposomes[32, 33], and most recently maghemite nanoparticles [34] with subsequent T1-weighted MRI and ferumoxtran-10 [35] with subsequent T2-weighted MRI have used to actively monitor drug distribution via CED infusion.

Gd-DTPA is a frequently used, readily available contrast agent that does not need to be specially prepared using expensive laboratory techniques like many other gadolinium derivatives (i.e. Gd-albumin and Gd-liposomes). This makes Gd-DTPA a technically and economically feasible option for imaging the early distribution of infused drug in large clinical trials. Low molecular weight molecules (i.e. Gd-DTPA) have higher diffusivities and removal rates than high molecular weight molecules (i.e. MR1-1 or other therapeutics) and therefore they exhibit drastically different volumes of distribution when co-infused. However, by measuring the loss rates of both molecules into cerebral capillaries, it may be possible to infuse the low molecular weight molecule at a concentration high enough to compensate for the difference in loss rates, therefore equalizing the distributions. After this adjustment is made, Gd-DTPA can be used as a surrogate tracer for MR1-1 and estimate the distribution of MR1-1 distribution on magnetic resonance imaging (MRI), assuming a short time scale of a few hours, so that the difference in diffusion rates does not complicate our calculations. Further calculations are necessary to estimate the distribution of longer infusions, but the approach is similar.

We propose the intracerebral co-infusion of Gd-DTPA along with MR1-1 via CED to actively monitor drug distribution during infusion. There are previously published reports of safe intracerebral delivery of Gd-DTPA into the brain, but they are all limited by either involving very few subjects[36, 37] or assessed only short-term safety immediately following infusion[10, 27] There have been no published pre-clinical animal studies assessing the long term safety and toxicity of intracerebral MR1-1 infusion and co-infusion of Gd-DTPA. In our study we systematically determine the effect of CED infusion of MR1-1 with and without co-infusion of Gd-DTPA.

\section{Materials and Methods}

\section{Intracerebral cannula implantation}

Immunocompetent male Fisher 344 rats were maintained in the Duke University Graduate Student Research Building II according to institutional policy. All rats were approximately 3 months old at the time of surgery. The rats were anesthetized prior to surgery with our standard regimen of an intraperitoneal (i.p.) injection of a 50:50 mixture of ketamine (55 $\mathrm{mg} / \mathrm{mL}$ stock solution) and xylazine $(9 \mathrm{mg} / \mathrm{mL}$ stock solution) at a dose of $1 \mathrm{mg} / \mathrm{kg}$. Following induction of anesthesia, they were placed into a stereotactic frame (Kopf Instruments, Tunjunga, CA). The cannula implantation procedure is the same as that 
previously described by us in Grossi et al. [38]. Briefly, a 25-gauge, 3-mm guide cannula (Plastics One, Inc., Roanoke, VA) was surgically implanted into the right caudate nucleus, 1 $\mathrm{mm}$ anterior and $3 \mathrm{~mm}$ lateral to the bregma. The cannula was then permanently secured to the calvarium with cranioplastic cement (Plastics One, Inc., Roanoke, VA). A dummy cannula (Plastics One, Inc., Roanoke, VA) was placed into the guide cannula to occlude the lumen and prevent infection, and the surgical incision was closed with staples. The rats were given at least one week to recover from cannula implantation before undergoing the next series of operations for pump implantation.

After successful completion of cannula implantation, all healthy rats that showed normal weight, no neurological deficit, and no evidence of infection were then assigned a randomly generated number between 1 and 40. Rats were then equally divided into four groups labeled A-D, such that rats 1-10 were in group A, 2-20 in group B, 3-30 in group C, and 4-40 in group D. All infusions consisted of differing concentrations of MR1-1 and Gd-DTPA mixed in $0.2 \%$ HSA (Grifols USA, LLC, Los Angeles, CA) and $0.9 \%$ normal saline. Albumin is routinely co-infused with drugs to prevent non-specific binding and sequestration of drugs in the catheter tubing. Group A received $25 \mathrm{ng} / \mathrm{mL}$ MR1-1, Group B received $7 \mu \mathrm{mol} / \mathrm{mL}$ GdDTPA (Bayer HealthCare Pharmaceuticals Inc., Wayne, NJ), Group C received $25 \mathrm{ng} / \mathrm{mL}$ MR1-1 with $7 \mu \mathrm{mol} / \mathrm{mL}$ Gd-DTPA, and Group D received $250 \mathrm{ng} / \mathrm{mL}$ MR1-1 with $7 \mu \mathrm{mol} /$ mL Gd-DTPA.

\section{Infusate preparation}

The osmotic pumps infuse at a constant rate of $10 \mu \mathrm{L} / \mathrm{hr}$. In order to ensure an adequate supply of infusate for 5 days of continual infusion (1.2 mL of infusate over 120 hours), 25 $\mathrm{mL}$ of infusate was made for each group. For infusate \#A, $14.06 \mathrm{~mL}$ of normal saline was mixed with $10.94 \mathrm{~mL}$ of $0.457 \%$ purified HSA stock solution and $1.6 \mu \mathrm{L}$ of MR1-1 stock solution for a total volume of $25 \mathrm{~mL}$. For infusate \#B, $13.71 \mathrm{~mL}$ of normal saline was mixed with $10.94 \mathrm{~mL}$ of $0.457 \%$ purified HSA stock solution and $0.35 \mathrm{~mL}$ of Gd-DTPA stock solution for a total volume of $25 \mathrm{~mL}$. For infusate $\# \mathrm{C}, 13.71 \mathrm{~mL}$ of normal saline was mixed with $10.94 \mathrm{~mL}$ of $0.457 \%$ purified HSA stock solution, $0.35 \mathrm{~mL}$ of Gd-DTPA stock solution, and $1.6 \mu \mathrm{L}$ of MR1-1 stock solution for a total volume of $25 \mathrm{~mL}$. For infusate \#D, $13.69 \mathrm{~mL}$ of normal saline was mixed with $10.94 \mathrm{~mL}$ of $0.457 \%$ purified HSA stock solution, $0.35 \mathrm{~mL}$ of Gd-DTPA stock solution, and $16 \mu \mathrm{L}$ of MR1-1 stock solution for a total volume of $25 \mathrm{~mL}$. Table 1 summarizes the final concentrations of each infusate component for all four groups.

\section{Pump implantation and CED infusion}

CED infusion was performed by an Alzet osmotic pump (Product 2MLI, ALZA Corp., Palo Alto, CA) connected by silicon tubing (Molded Rubber and Plastics, Butler, WI) to a 33gauge, $7-\mathrm{mm}$ infusion cannula (Plastics One, Inc.). The pumps were primed at $37^{\circ} \mathrm{C}$ for 24 hours before implantation. Again, the rats were anesthetized prior to surgery with an intraperitoneal (i.p.) injection of ketamine $(55 \mathrm{mg} / \mathrm{mL})$ and xylazine $(9 \mathrm{mg} / \mathrm{mL})$ at a dose of $1 \mathrm{mg} / \mathrm{kg}$. During pump implantation, the 33-gauge infusion cannula was inserted into the previously implanted 25-gauge guide cannula and the pump was implanted subcutaneously over the right shoulder. The pump was secured in place with surgical staples. The pumps were left in for 5 days, after which the rats were anesthetized with an intraperitoneal (i.p.) injection of ketamine $(55 \mathrm{mg} / \mathrm{mL})$ and xylazine $(9 \mathrm{mg} / \mathrm{mL})$ at a dose of $1 \mathrm{mg} / \mathrm{kg}$, the pumps were explanted and the skin wounds were closed with surgical staples.

\section{Assessment of toxicity}

Toxicity was monitored by measuring the rats' weights three times per week and by daily neurological function tests, consisting of stepping and placing reflex, incline ramp climbing 
ability, beginning immediately following infusion initiation and continuing throughout the six-week observation period. At the end of the 6 week study period, the rats were sacrificed by overdose with isoflurane. A full necropsy was performed and the neuroaxis was fixed in buffered neutral formalin for 7 days, and then placed in a decalcifying solution for 48 hours. Six coronal sections of the neuroaxis were subsequently taken for histological examination, including (1) brain at the level of cannula implantation near the coronal suture and pituitary gland, (2) brain at the level of the cerebellum, (3) cervical spine, (4) thoracic spine, (5) lumbar spine, and (6) cauda equina. The sections were fixed in formalin and sent to pathology for analysis, where they were embedded in paraffin. $6 \mu \mathrm{m}$ sections were stained with Luxol fast blue and hematoxylin and eosin (H\&E) and examined by light microscopy.

\section{Results}

\section{Survival}

No deaths occurred during the six week observation period in any of the four groups.

\section{Toxicity Monitoring}

There was no evidence of neurological toxicity in any of the rats during daily assessments either during infusion or in the subsequent six-week observation window. None of the rats exhibited any characteristic signs of neurological deficits such as head tilt, hemiparesis, or ataxic gait. By the end of the six-week period, an increase in weight groups as compared to baseline at the start of infusion was seen in all groups (Figure 1). The pattern of percent weight gain over time was shown by a repeated measures analysis to be consistent across the 4 groups ( $>0.999$ for interaction between group and time). The final average weight changes with standard deviations for each group are as follows: Group A showed a $12.9 \pm 10.674 \%$ increase, group B showed a $13.2 \pm 12.748 \%$ increase, group C showed a $9.2 \pm 6.649 \%$ increase, and group D showed a $14.1 \pm 14.449 \%$ increase.

\section{Histological assessment}

On light microscopy, all sections of the neuraxes of all rats in the study showed no histological toxicity that could be attributed to infusion of the study drugs. Meninges, grey matter, and white matter were examined. There was no evidence of neuronal loss. No neuronal eosinophilia, necrosis, or ischemia was seen. There was no vasculitis or granulomatous inflammation. Macrophages and reactive astrogliosis were seen in sections taken around the intracerebral cannula tract where the guide cannula had been inserted, and was consistent across all specimens (Figure 2). Additionally, it should be noted that gross inspection of the major internal organs at time of necropsy revealed no significant abnormalities in any of the study rats.

\section{Discussion}

Despite standard of care treatment, which includes gross total resection and subsequent XRT with concurrent temozolomide, the prognosis for GBMs remains poor [15]. EGFRvIII is a mutant EGFR with a gain of function constitutively active tyrosine kinase that promotes unregulated cell growth and division [18]. It is a unique and powerful target for GBM therapy because although it is expressed on tumor cells in $40 \%$ of patients, it is not normally expressed on any adult tissues [19]. MR1-1 is a glioma-specific recombinant immunotoxin that targets the genetically modified Pseudomonas exotoxin PE-38 to tumor cells via a conjugated anti-EGFRvIII monoclonal antibody fragment. We believe that direct intracerebral delivery of MR1-1 immunotoxin into the tumor tissue via strategically placed CED catheters will effectively treat GBM that expresses the EGFRvIII antigen. 
The same property of the BBB that prevents drugs from entering the CNS should theoretically also keep intracerebrally administered drugs from leaking into systemic circulation to some degree. While this may not be a complete blockade, evidence from previous CED trials has not discovered any significant systemic toxicity. This may also be due to the profoundly lower total drug dose required for effective therapy by CED compared to systemic intravenous delivery. Additionally, because CED is pressure-driven, the concentration of high molecular weight agents (i.e. immunotoxins) is constant across a predictable distance from the catheter annulus before dropping off steeply at the drug distribution boundaries. This allows for delivery of high concentrations of powerful chemotherapeutics into the tumor bed while limiting neurotoxicity. The putative distribution of MR1-1 and Gd-DTPA in this pre-clinical rat model is based on the position of the catheter tip and the composition of neural tissue surrounding the tip. The purported position of the catheter tip is in the caudate nucleus, which is relatively homogeneous gray matter. As such, the infusate should distribute evenly along the gray matter. However, if there is sufficient retrograde flow, or backflow, along the catheter tract such that the infusate comes into contact with a white matter tract, subarachnoid space or intraventricular space, the infusate will flow along the path of least resistance causing subsequent leakage along white matter tracts or into a subarachnoid or intraventricular space[28].

It has been shown that proper CED catheter placement is able to achieve intraparenchymal distribution into the tumor bed, resulting in maximal drug efficacy. In contrast, improperly or poorly positioned catheters will result in immediate or delayed infusate leakage, leading to minimal drug efficacy[24]. Current attempts to actively monitor drug distribution using conventional MRI imaging with involve expensive and, at times, cumbersome surrogate tracers such as Gd-albumin conjugates[29-31], Gd-liposomes[32, 33], maghemite nanoparticles [34] and ferumoxtran-10[35]. We propose the use of the relatively inexpensive and readily available low molecular weight imaging tracer Gd-DTPA to actively monitor such leakage of infused therapeutics, which in this study is the high molecular weight immunotoxin MR1-1. The half-life of MR1-1 is currently unknown and will need to be measured in future studies. However, we do not believe that the half-life of MR1-1 will be affected by co-infusion of Gd-DTPA. Gd-DTPA is an important option for the monitoring of CED infusate distribution because it is easily accessible, commonly used, and does not require complicated or extensive preparation.

In order to use Gd-DTPA for accurate monitoring of high molecular weight therapeutics, a number of calculations need to be made. Gd-DTPA, by virtue of its lower molecular weight, will both diffuse faster through neural tissue and be removed faster via loss into cerebral capillaries than MR1-1. On a short time scale of a few hours, the difference in diffusion is minor and can be ignored, so only the differences in removal rates between the two molecules would need to be considered. By measuring the loss rates for each molecule using special computational algorithms on standard MR images taken in vivo during constant drug infusion, one can determine how much more Gd-DTPA is lost per unit time than MR1-1. This difference in removal than can be overcome by infusing Gd-DTPA at a higher concentration that is equal to the concentration of MR1-1 multiplied by the ratio of the GdDTPA:MR1-1 removal rate. This correction factor will make the difference in removal rates between the two molecules effectively equivalent, and therefore a low molecular weight tracer like Gd-DTPA may reliably mimic the distribution of MR1-1 in the first hours of infusion. For longer time scales, additional calculations are also required since the higher diffusion of lower molecular weight molecules like Gd-DTPA will widen the distribution of Gd-DTPA when compared to higher molecular weight molecules like MR1-1. Without correcting for diffusion in these longer infusion situations, the distribution of Gd-DTPA seen on MRI would be greater than the distribution of MR1-1. However, these diffusivity differences can also be measured and the difference in diffusion rates can also be 
compensated in order to provide an accurate prediction of drug distribution with low molecular weight tracer molecules even at longer time frames. While the details of these calculations are complex and beyond the scope of this paper, monitoring the distribution of CED infusion of free unconjugated Gd-DTPA may be able to effectively predict the distribution of MR1-1 for both short and long time periods but will need to be validated experimentally. This technique may allow for the use of free gadolinium as a surrogate tracer in future CED studies in humans. With the proper understanding of transport phenomena and practical imaging of CED using Gd-DTPA, we may be able to accurately confine drug distribution to a pre-determined area (i.e. the tumor).

We plan to test the ability of free Gd-DTPA to monitor the distribution of larger molecules such as MR1-1 in future human clinical trials by co-infusing radiolabelled ${ }^{123}$ I-HSA which, in combination with SPECT imaging, is able to monitor drug distribution in a clinical setting[39]. If free Gd-DTPA is able to successfully monitor MR1-1 distribution, it has the potential to become the standard imaging modality for active CED infusion monitoring due to its wide availability and ease of use in conjunction with standard MRI sequences. With the ability to accurately monitor CED infusion would come the ability to alter catheter positioning based on drug distribution. In a hypothetical case in which leakage was detected, the catheter trajectories could be adjusted so that more of the immunotoxin could reach the targeted area. Ultimately, should Gd-DTPA co-infusion for the purposes of monitoring volume of distribution prove to be effective, we will be able to minimize infusate leakage while maximizing the efficacy of MR1-1 on GBM.

\section{Conclusions}

In conclusion, we have shown in our systematic pre-clinical study that CED infusion of MR1-1 is safe over a range of doses. Groups A and C in our study also serve as simulations for co-infusion with Gd-DTPA, which can then be imaged using MRI to allow for real-time monitoring of MR1-1 distribution. If the infusate is determined to be leaking into the subarachnoid or intraventricular spaces or if there is inadequate distribution throughout the tumor bed, then catheter trajectory and placement can be changed immediately. We predict that the overall effect of CED administration of MR1-1 immunotoxin with co-infusion of Gd-DTPA will be high levels of tumor killing with sparing of normal neural tissue and absence of systemic adverse effects using active MRI monitoring of drug distribution via the surrogate imaging tracer Gd-DTPA, making this an ideal infusion therapy to treat GBM.

\section{Acknowledgments}

We acknowledge the expert technical assistance provided by Gary Archer, Tracy Chewning, and April Coan.

This research was supported in part by Duke University's CTSA grant TL1RR024126 from National Center for Research Resources, National Institutes of Health and by the Intramural Research Program of the National Institutes of Health, National Cancer Institute, Center for Cancer Research.

\section{References}

1. Bobo RH, Laske DW, Akbasak A, Morrison PF, Dedrick RL, Oldfield EH. Convection-enhanced delivery of macromolecules in the brain. Proc Natl Acad Sci U S A. 1994; 91:2076-2080. [PubMed: 8134351]

2. Sampson JH, Akabani G, Archer GE, Berger MS, Coleman RE, Friedman AH, Friedman HS, Greer K, Herndon JE 2nd, Kunwar S, McLendon RE, Paolino A, Petry NA, Provenzale JM, Reardon DA, Wong TZ, Zalutsky MR, Pastan I, Bigner DD. Intracerebral infusion of an EGFR-targeted toxin in recurrent malignant brain tumors. Neuro Oncol. 2008; 10:320-329. [PubMed: 18403491] 
3. Vogelbaum MA. Convection enhanced delivery for treating brain tumors and selected neurological disorders: symposium review. J Neurooncol. 2007; 83:97-109. [PubMed: 17203397]

4. Weaver M, Laske DW. Transferrin receptor ligand-targeted toxin conjugate (Tf-CRM107) for therapy of malignant gliomas. J Neurooncol. 2003; 65:3-13. [PubMed: 14649881]

5. Weber F, Asher A, Bucholz R, Berger M, Prados M, Chang S, Bruce J, Hall W, Rainov NG, Westphal M, Warnick RE, Rand RW, Floeth F, Rommel F, Pan H, Hingorani VN, Puri RK. Safety, tolerability, and tumor response of IL4-Pseudomonas exotoxin (NBI-3001) in patients with recurrent malignant glioma. J Neurooncol. 2003; 64:125-137. [PubMed: 12952293]

6. Vogelbaum MA, Sampson JH, Kunwar S, Chang SM, Shaffrey M, Asher AL, Lang FF, Croteau D, Parker K, Grahn AY, Sherman JW, Husain SR, Puri RK. Convection-enhanced delivery of cintredekin besudotox (interleukin-13-PE38QQR) followed by radiation therapy with and without temozolomide in newly diagnosed malignant gliomas: phase 1 study of final safety results. Neurosurgery. 2007; 61:1031-1037. discussion 1037-1038. [PubMed: 18091279]

7. Bankiewicz KS, Eberling JL, Kohutnicka M, Jagust W, Pivirotto P, Bringas J, Cunningham J, Budinger TF, Harvey-White J. Convection-enhanced delivery of AAV vector in parkinsonian monkeys; in vivo detection of gene expression and restoration of dopaminergic function using prodrug approach. Exp Neurol. 2000; 164:2-14. [PubMed: 10877910]

8. Oiwa Y, Sanchez-Pernaute R, Harvey-White J, Bankiewicz KS. Progressive and extensive dopaminergic degeneration induced by convection-enhanced delivery of 6-hydroxydopamine into the rat striatum: a novel rodent model of Parkinson disease. J Neurosurg. 2003; 98:136-144. [PubMed: 12546362]

9. Zirzow GC, Sanchez OA, Murray GJ, Brady RO, Oldfield EH. Delivery, distribution, and neuronal uptake of exogenous mannose-terminal glucocerebrosidase in the intact rat brain. Neurochem Res. 1999; 24:301-305. [PubMed: 9972879]

10. Lonser RR, Schiffman R, Robison RA, Butman JA, Quezado Z, Walker ML, Morrison PF, Walbridge S, Murray GJ, Park DM, Brady RO, Oldfield EH. Image-guided, direct convective delivery of glucocerebrosidase for neuronopathic Gaucher disease. Neurology. 2007; 68:254-261. [PubMed: 17065591]

11. Lonser RR, Walbridge S, Murray GJ, Aizenberg MR, Vortmeyer AO, Aerts JM, Brady RO, Oldfield EH. Convection perfusion of glucocerebrosidase for neuronopathic Gaucher's disease. Ann Neurol. 2005; 57:542-548. [PubMed: 15786474]

12. Fisher RS, Ho J. Potential new methods for antiepileptic drug delivery. CNS Drugs. 2002; 16:579593. [PubMed: 12153331]

13. Fisher RS, Chen DK. New routes for delivery of anti-epileptic medications. Acta Neurol Taiwan. 2006; 15:225-231. [PubMed: 17214084]

14. Primary brain tumors in the United States statistical report. Central Brain Tumor Registry of the United States

15. Stupp R, Mason WP, van den Bent MJ, Weller M, Fisher B, Taphoorn MJ, Belanger K, Brandes AA, Marosi C, Bogdahn U, Curschmann J, Janzer RC, Ludwin SK, Gorlia T, Allgeier A, Lacombe D, Cairncross JG, Eisenhauer E, Mirimanoff RO. Radiotherapy plus concomitant and adjuvant temozolomide for glioblastoma. N Engl J Med. 2005; 352:987-996. [PubMed: 15758009]

16. Hegi ME, Diserens AC, Gorlia T, Hamou MF, de Tribolet N, Weller M, Kros JM, Hainfellner JA, Mason W, Mariani L, Bromberg JE, Hau P, Mirimanoff RO, Cairncross JG, Janzer RC, Stupp R. MGMT gene silencing and benefit from temozolomide in glioblastoma. N Engl J Med. 2005; 352:997-1003. [PubMed: 15758010]

17. Humphrey PA, Wong AJ, Vogelstein B, Zalutsky MR, Fuller GN, Archer GE, Friedman HS, Kwatra MM, Bigner SH, Bigner DD. Anti-synthetic peptide antibody reacting at the fusion junction of deletion-mutant epidermal growth factor receptors in human glioblastoma. Proc Natl Acad Sci U S A. 1990; 87:4207-4211. [PubMed: 1693434]

18. Chu CT, Everiss KD, Wikstrand CJ, Batra SK, Kung HJ, Bigner DD. Receptor dimerization is not a factor in the signalling activity of a transforming variant epidermal growth factor receptor (EGFRvIII). Biochem J. 1997; 324(Pt 3):855-861. [PubMed: 9210410] 
19. Moscatello DK, Holgado-Madruga M, Godwin AK, Ramirez G, Gunn G, Zoltick PW, Biegel JA, Hayes RL, Wong AJ. Frequent expression of a mutant epidermal growth factor receptor in multiple human tumors. Cancer Res. 1995; 55:5536-5539. [PubMed: 7585629]

20. Wikstrand CJ, Hale LP, Batra SK, Hill ML, Humphrey PA, Kurpad SN, McLendon RE, Moscatello D, Pegram CN, Reist CJ, et al. Monoclonal antibodies against EGFRvIII are tumor specific and react with breast and lung carcinomas and malignant gliomas. Cancer Res. 1995; 55:3140-3148. [PubMed: 7606735]

21. Pastan I, FitzGerald D. Recombinant toxins for cancer treatment. Science. 1991; 254:1173-1177. [PubMed: 1683495]

22. Pastan I, Chaudhary V, FitzGerald DJ. Recombinant toxins as novel therapeutic agents. Annu Rev Biochem. 1992; 61:331-354. [PubMed: 1497314]

23. Ochiai H, Archer GE, Herndon JE 2nd, Kuan CT, Mitchell DA, Bigner DD, Pastan IH, Sampson JH. EGFRvIII-targeted immunotoxin induces antitumor immunity that is inhibited in the absence of CD4+ and CD8+ T cells. Cancer Immunol Immunother. 2008; 57:115-121. [PubMed: 17634939]

24. Sampson JH, Brady ML, Petry NA, Croteau D, Friedman AH, Friedman HS, Wong T, Bigner DD, Pastan I, Puri RK, Pedain C. Intracerebral infusate distribution by convection-enhanced delivery in humans with malignant gliomas: descriptive effects of target anatomy and catheter positioning. Neurosurgery. 2007; 60:ONS89-98. discussion ONS98-89. [PubMed: 17297371]

25. Sampson JH, Raghavan R, Provenzale JM, Croteau D, Reardon DA, Coleman RE, Ponce I Rodriguez, Pastan I, Puri RK, Pedain C. Induction of hyperintense signal on T2-weighted MR images correlates with infusion distribution from intracerebral convection-enhanced delivery of a tumor-targeted cytotoxin. AJR Am J Roentgenol. 2007; 188:703-709. [PubMed: 17312057]

26. Mardor Y, Roth Y, Lidar Z, Jonas T, Pfeffer R, Maier SE, Faibel M, Nass D, Hadani M, Orenstein A, Cohen JS, Ram Z. Monitoring response to convection-enhanced taxol delivery in brain tumor patients using diffusion-weighted magnetic resonance imaging. Cancer Res. 2001; 61:4971-4973. [PubMed: 11431326]

27. Mardor Y, Rahav O, Zauberman Y, Lidar Z, Ocherashvilli A, Daniels D, Roth Y, Maier SE, Orenstein A, Ram Z. Convection-enhanced drug delivery: increased efficacy and magnetic resonance image monitoring. Cancer Res. 2005; 65:6858-6863. [PubMed: 16061669]

28. Raghavan R, Brady ML, Rodriguez-Ponce MI, Hartlep A, Pedain C, Sampson JH. Convectionenhanced delivery of therapeutics for brain disease, and its optimization. Neurosurg Focus. 2006; 20:E12. [PubMed: 16709017]

29. Nguyen TT, Pannu YS, Sung C, Dedrick RL, Walbridge S, Brechbiel MW, Garmestani K, Beitzel $\mathrm{M}$, Yordanov AT, Oldfield EH. Convective distribution of macromolecules in the primate brain demonstrated using computerized tomography and magnetic resonance imaging. J Neurosurg. 2003; 98:584-590. [PubMed: 12650432]

30. Murad GJ, Walbridge S, Morrison PF, Garmestani K, Degen JW, Brechbiel MW, Oldfield EH, Lonser RR. Real-time, image-guided, convection-enhanced delivery of interleukin 13 bound to pseudomonas exotoxin. Clin Cancer Res. 2006; 12:3145-3151. [PubMed: 16707614]

31. Lonser RR, Walbridge S, Garmestani K, Butman JA, Walters HA, Vortmeyer AO, Morrison PF, Brechbiel MW, Oldfield EH. Successful and safe perfusion of the primate brainstem: in vivo magnetic resonance imaging of macromolecular distribution during infusion. J Neurosurg. 2002; 97:905-913. [PubMed: 12405380]

32. Saito R, Krauze MT, Bringas JR, Noble C, McKnight TR, Jackson P, Wendland MF, Mamot C, Drummond DC, Kirpotin DB, Hong K, Berger MS, Park JW, Bankiewicz KS. Gadolinium-loaded liposomes allow for real-time magnetic resonance imaging of convection-enhanced delivery in the primate brain. Exp Neurol. 2005; 196:381-389. [PubMed: 16197944]

33. Saito R, Bringas JR, McKnight TR, Wendland MF, Mamot C, Drummond DC, Kirpotin DB, Park JW, Berger MS, Bankiewicz KS. Distribution of liposomes into brain and rat brain tumor models by convection-enhanced delivery monitored with magnetic resonance imaging. Cancer Res. 2004; 64:2572-2579. [PubMed: 15059914]

34. Perlstein B, Ram Z, Daniels D, Ocherashvilli A, Roth Y, Margel S, Mardor Y. Convectionenhanced delivery of maghemite nanoparticles: Increased efficacy and MRI monitoring. Neuro Oncol. 2008; 10:153-161. [PubMed: 18316474] 
35. Szerlip NJ, Walbridge S, Yang L, Morrison PF, Degen JW, Jarrell ST, Kouri J, Kerr PB, Kotin R, Oldfield EH, Lonser RR. Real-time imaging of convection-enhanced delivery of viruses and virussized particles. J Neurosurg. 2007; 107:560-567. [PubMed: 17886556]

36. Lonser RR, Warren KE, Butman JA, Quezado Z, Robison RA, Walbridge S, Schiffman R, Merrill M, Walker ML, Park DM, Croteau D, Brady RO, Oldfield EH. Real-time image-guided direct convective perfusion of intrinsic brainstem lesions. Technical note. J Neurosurg. 2007; 107:190197. [PubMed: 17639894]

37. Murad GJ, Walbridge S, Morrison PF, Szerlip N, Butman JA, Oldfield EH, Lonser RR. Imageguided convection-enhanced delivery of gemcitabine to the brainstem. J Neurosurg. 2007; 106:351-356. [PubMed: 17410722]

38. Grossi PM, Ochiai H, Archer GE, McLendon RE, Zalutsky MR, Friedman AH, Friedman HS, Bigner DD, Sampson JH. Efficacy of intracerebral microinfusion of trastuzumab in an athymic rat model of intracerebral metastatic breast cancer. Clin Cancer Res. 2003; 9:5514-5520. [PubMed: 14654531]

39. Sampson JH, Raghavan R, Brady ML, Provenzale JM, Herndon JE 2nd, Croteau D, Friedman AH, Reardon DA, Coleman RE, Wong T, Bigner DD, Pastan I, Rodriguez-Ponce MI, Tanner P, Puri R, Pedain C. Clinical utility of a patient-specific algorithm for simulating intracerebral drug infusions. Neuro Oncol. 2007; 9:343-353. [PubMed: 17435179] 


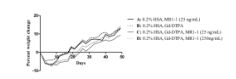

Figure 1.

Percent change in weights over time for all groups. No statistically significant difference in weight change between the different groups was found. Across all study groups, overall weight increased from baseline by the end of the six-week period. 


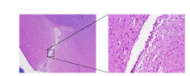

Figure 2.

Photomicrograph of an H\&E stain of a representative coronal cross-section of rat brain from one of the study rats shown at $4 \times$ magnification (left) and $20 \times$ magnification (right). Only gliosis along the catheter tract was seen, with no unexpected pathological findings. 
Table 1

Study Group Infusate Concentrations

\begin{tabular}{|c|c|c|c|}
\hline Group & HSA & MR1-1 & Gd-DTPA \\
\hline A & $0.2 \%$ & $25 \mathrm{ng} / \mathrm{mL}$ & 0 \\
\hline B & $0.2 \%$ & 0 & $7 \mu \mathrm{mol} / \mathrm{mL}$ \\
\hline C & $0.2 \%$ & $25 \mathrm{ng} / \mathrm{mL}$ & $7 \mu \mathrm{mol} / \mathrm{mL}$ \\
\hline D & $0.2 \%$ & $250 \mathrm{ng} / \mathrm{mL}$ & $7 \mu \mathrm{mol} / \mathrm{mL}$ \\
\hline
\end{tabular}

